\title{
Comunicación y cultura
}

Gabriela Fabbro

Facultad de Comunicación, Universidad Austral

gfabbro@austral.edu.ar

DOI: https://doi.org/10.26422/aucom.2020.0902.fab

El presente monográfico está focalizado en las relaciones entre comunicación y cultura. La diversidad de enfoques y abordajes permitió la recepción de propuestas desde todas las disciplinas científicas y humanísticas que investigan cualquier aspecto de la cultura contemporánea en relación con la comunicación.

La globalización, el auge de las redes sociales a partir del año 2000, las nuevas formas y hábitos de consumo, las formas alternativas de producción, el usuario como coconstructor de contenidos, la convergencia tecnológica y la diversidad, nos ponen en el desafío de comprender la influencia y el poder de los medios como instituciones sociales, y su papel en la producción de la cultura.

Tanto la cultura como la comunicación son conceptos muy desarrollados por las ciencias sociales. Desde disciplinas como la Sociología y la Antropología, la mayoría de definiciones de cultura ponen el acento en estas características: se basa en símbolos universales que ayudan a comunicarnos; se comparte entre las diferentes personas; $y$, por último, es aprendida o adquirida. Así, cultura se refiere a la existencia de símbolos que ayudan a comunicarse a los seres humanos, la cultura se transmite y, por tanto, necesita de medios para su difusión; y, por último, el aprendizaje y la adquisición de cultura también implican formas comunicativas de mediación entre sujetos, o entre dispositivos y sujetos o entre instituciones y sujetos.

Por ello, comunicación y cultura son dos universos inseparables, interdependientes; son el uno condición del otro. Siguiendo a Hall (1990): "La comunicación es inseparable de la cultura. Es el otro lado de la misma moneda. No puede existir la una sin la otra. La cultura es comunicación y la comunicación es cultura" (Hall, 1990, como se citó en M. López Herrera, 2015, s.p. ).

La comunicación es el mecanismo generador del diálogo y la convivencia de los sujetos sociales y dicho diálogo se sustenta a partir de la cultura como mecanismo organizador de la experiencia humana. Así los artículos seleccionados desarrollan ejes temáticos que ponen en escena la complejidad de esta relación en el contexto actual.

Iniciamos el camino que comparten la cultura y la comunicación a partir de los artículos que integran este número. 
El primer artículo, a cargo de Felicitas Casillo, estudiosa del discurso y de la hermenéutica y cautivante poeta, nos presenta, dentro de las caracterizaciones contemporáneas de la cultura, las distintas metáforas que sobre el patrimonio cultural ofrecen diversos tipos de textos de los diarios online La Nación, Clarín y Página/12, entre 2006 y 2011. A través del estudio del caso de la transformación institucional y remodelación edilicia del Teatro Colón, la metaforización funcionó como un mecanismo de representación de la cultura a partir del cual se concretan diversas caracterizaciones. Las familias metafóricas económica y religiosa, desde un enfoque hermenéutico, permiten concluir que una caracterización válida de cultura será aquella que albergue a los protagonistas de una tradición cultural.

En La influencia del contexto como práctica comunicacional, Santiago Aragón, docente de la Universidad de Lomas de Zamora, aborda los desafíos de la integración en la sociedad de la información. Su ensayo propone explorar la importancia de la comunicación y de los sistemas de información para la articulación entre las relaciones globales y las prácticas territoriales. Su texto indaga en las tensiones y las dinámicas de colaboración que resultan de la coexistencia entre la institucionalidad local y la Sociedad Red, entre lo global y lo local, entre territorio, espacio público y periferia.

Las condiciones sobre las que se construye la conversación pública se modifican en un escenario en el que la producción y la circulación de información ocupan el centro de la escena. Existen nuevos mecanismos que obligan a revisar la forma en que las instituciones políticas y las organizaciones mediáticas gestionan sus canales de expresión y discusión. La distinción entre una espacialidad capaz de sobrevivir en la convivencia con la sociedad de la información y otra que queda excluida permite reflexionar, a su vez, sobre las condiciones de adaptación. El interrogante es en qué medida las posibilidades de emerger de las identidades locales están relacionadas con su capacidad de expresarse y vincularse, en el marco de una práctica comunicacional que vincule la influencia de lo global con la vigencia de lo cultural. ¿Los territorios logran inscribir sus prácticas particulares en el registro que propone la Sociedad Red? La potencialidad de convertir lo periférico en contexto, integrando lo local a través de dinámicas colaborativas, surge como un campo común que integra, en su análisis, la cultura y la comunicación.

En consonancia con el sendero abierto por el artículo anterior, Raúl Rivadeneira Prada (1997) nos plantea:

La idea central es que la sociedad globalmente considerada es emisora permanente de mensajes de variada índole. Lo urbano, lo rural, son espacios de intensa producción cultural y al mismo tiempo ámbito de difusión de mensajes elaborados por los medios masivos, para los cuales la cultura popular suele ser marginal y por lo tanto subvaluado, cuando no neutralizado (s. p.). 
Y por ello el tercer artículo, a cargo de Diego Pérez, de FLACSO Ecuador, analiza las representaciones que el diario El Comercio de ese país ofrece en su producción periodística con motivo de la protesta social de octubre de 2019, dentro del marco de la Ley Orgánica de Comunicación (LOC) y la Constitución del Estado ecuatoriano, norma que plantea el derecho a la difusión de contenidos de pueblos originarios y diferentes nacionalidades a partir de contenidos basados en la interculturalidad y pluriculturalidad. Toda la información analizada ratifica la permanencia del estigma y la subvaloración del indígena como sujeto político. Dicha mirada estigmatizante se da tanto en la disputa por el espacio público como en el plano de la legitimidad y la participación política, es decir, una construcción del imaginario discriminatorio en contra del indígena desde el discurso mediático de este periódico. Categorías como exclusión social, formas de diferenciación y legitimización de lógicas de acumulación y proyectos hegemónicos pretenden describir la participación del sector indígena en el paro de octubre con el anclaje en un ejemplo de la prensa ecuatoriana, desde la perspectiva de la interculturalidad.

Luego de estos textos que toman la relación entre la cultura y la comunicación como un escenario de disputas, metáforas y desafíos, el cuarto artículo, a cargo de Inmaculada Sánchez-Labella Martín, del Departamento de Comunicación Audiovisual y Publicidad de la Universidad de Sevilla, nos invita al mundo de los youtubers infantiles como generadores de nuevas canales para la publicidad de diferentes productos. Mediante una metodología mixta cualitativo-descriptiva se recorren las marcas presentes en los canales de estos nuevos actores en el circuito audiovisual digital de la persuasión y se los analiza como personajes que se han convertido en referentes para sus seguidores. Así, desde el punto de vista de su dimensión iconográfica, psicológica y sociológica, propias de los personajes de ficción, se comprueba que no siempre las marcas corporativas están siempre presentes en sus producciones y termina prevaleciendo la construcción del personaje que han creado a partir de una identidad que se sostiene en estereotipos, los cuales, en algunos casos, transmiten actitudes y comportamientos con consecuencias negativas para el público infantil que los sigue.

Seguidamente Ana Sedeño-Valdellós, de la Universidad de Málaga, nos lleva al mundo del videoclip musical a partir del análisis del canal Music Video Land de Vimeo con la intención de comprobar que las plataformas de video se han convertido en la forma central en la que se consumen y comparten contenidos visuales para la música popular y una principal fuente de negocio empresarial. Si bien YouTube es la más conocida y estudiada, este trabajo presenta un análisis del videoclip musical con más $M e$ gusta en el canal Music Video Land de Vimeo, dato supervisado por autores de IMVdb (The Internet Music Video Database), principal plataforma especializada de archivo y clasificación de videos musicales de internet y concluye que el videoclip conceptual de 
Gabriela Fabbro

Comunicación y cultura

música dance/electrónica e indie, con una importante presencia de técnicas avanzadas de realización y composición de imagen, resulta el más elegido por los comisarios y usuarios del canal. Este género subvalorado en el campo audiovisual es el de mayor experimentación. El caso analizado presenta un relato que apunta a la no-narratividad basada en lo conceptual y en técnicas novedosas de modificación espaciotemporal potenciadas por procesos digitales de postproducción.

Este recorrido nos lleva al artículo de Emiliano Vargas, docente de la Universidad de Buenos Aires quien nos presenta, desde una propuesta teórica que se enmarca en el concepto de Cultura de tradición lotmaniana el análisis de Jams de Black Music en Buenos Aires. Se denominan Jams de Black Music a un tipo de colectivos culturales que se encuentran en expansión en Buenos Aires. Con distintos niveles de trayectorias, convocatoria y organización realizan periódicamente performances en vivo con características no investigadas hasta ahora, a la vez que mantienen una activa vida online a través de sus ecosistemas mediáticos. A través de los casos Afromama y Skill Session se propone una tipología de performance en el nivel off line y de sus propuestas de sus playlists en la plataforma Spotify y se analizan sus ecosistemas y dinámica de las mediatizaciones que construyen. El autor cierra con el planteo de interrogantes acerca de cómo deberá ser la producción del patrimonio musical en el futuro cercano a partir de estas nuevas narrativas.

Probablemente el contexto de la pandemia haya resignificado varias de las relaciones entre comunicación y cultura, así, Cristian Secul Giusti, docente e investigador de la Universidad Nacional de La Plata nos sumerge en un análisis discursivo de la canción "Isolation" ("Aislamiento"), de John Lennon del año 1970, con la intención de ubicarnos en el contexto de pandemia y cómo la fuerza del género del rock permite ratificar su función poética, política, social lo que lo convierte en un canal de expresión de temores y de expectativas. Desde una perspectiva discursivo-enunciativa, el autor recorre la lírica de la canción a partir de las tematizaciones y los procedimientos deícticos que ella presenta, con el objetivo de encontrar significados recurrentes sobre el concepto de aislamiento, a partir de un involucramiento del que la consume enfrentado a un enemigo anónimo como la pandemia. Una canción de medio siglo atrás pone en escena nuevamente cómo en un contexto, pasado, presente o futuro de situación de aislamiento, pandémico en este caso, el rock será siempre un canal de expresión y protesta.

El camino de la relación entre cultura y comunicación nos acerca al mundo del libro y al siguiente artículo, a cargo de Diego Vigna y Lucía Coppari, de la Universidad Nacional de Córdoba, quienes nos presentan a uno de los nuevos actores dentro del ecosistema editorial: las cuentas de bookstagrammers argentinas y la recomendación digital de literatura contemporánea. A partir de un abordaje descriptivo y analítico 
de cuatro cuentas de Instagram dedicadas a la recomendación de libros basada en sus propios acopios de lecturas, se llega a comprobar un distanciamiento de las rutinas de la crítica literaria asociada a la herencia de publicaciones impresas en la Argentina, y un acercamiento a herramientas de difusión y consumo cultural que propician la caracterización de interacciones desplegadas entre recomendadores, lectores, autores y también editores. Las herramientas de difusión canónicas conviven, gracias a la heterogeneidad del sector editorial independiente, con nuevas formas de relación entre autores y lectores, a partir de una ética horizontal, basada en una dinámica interactiva e hipermedial.

Finalmente, los dos últimos artículos se focalizan en las editoriales alternativas, una universitaria y otras dos independientes, y dialogan sobre cómo la comunicación digital y los cambios en los procesos de difusión de sus contenidos, han traído consecuencias desafiantes e innovadoras en sus campañas de comunicación. El caso EDUVIM, presentado por Ivana Mihal, doctora en filosofía e investigadora del CONICET en el área de la Antropología, nos presenta la situación de las editoriales universitarias en el contexto de la convergencia digital. En el marco de la Red de Editoriales de Universidad Nacionales de Argentina (REUN), la autora se focaliza en la editorial de la Universidad Nacional de Villa María, Córdoba, Argentina a partir del análisis de tres roles: como marca en el mercado editorial, luego como modelo de edición universitaria y finalmente como parte de una estructura universitaria de gestión pública. El estudio muestra cómo estos sellos muchas veces no cuentan en sus equipos con integrantes especializados en comunicación digital o con conocimientos específicos en comunicación. A su vez, explica la complejidad de editar libros en el marco de una universidad, en la cual la comunicación digital de las editoriales requiere muchas veces adecuarse a los criterios más generales de estas instituciones, lo que las hace perder capacidad y riqueza a la hora de difundir sus catálogos. El trabajo es de carácter cualitativo y se basa en fuentes de información primarias y secundarias provenientes de observaciones participantes, entrevistas, relevamientos de información, webs y redes sociales.

Por su parte, Gustavo Velázquez nos ofrece una mirada sobre las editoriales independientes Eterna Cadencia y Santiago Arcos frente al proceso de la distribución. El profesor de la Universidad Nacional de Quilmes tiene por objetivo describir la disyuntiva que algunas editoriales tienen al decidir romper con el proceso clásico de distribución de sus contenidos y arriesgarse a hacerlo por ellas mismas. Por ello, algunos editores recurren a la contratación de empresas de distribución y otros deciden encarar la tarea por cuenta propia. Ambos métodos poseen sus propias particularidades, los cuales se pretenden analizar en el marco de este artículo. Una de las miradas más 
Gabriela Fabbro

Comunicación y cultura

interesantes que aporta este artículo es cómo la bibliodiversidad puede verse afectada según el modo de distribución que se adopte.

Para llegar al final de este recorrido en que comunicación, cultura y sociedad conviven y generan diálogos y nuevas estrategias, cerramos nuestro número con el breve pero profundo artículo del doctor Pedro Luis Barcia, a quien va dedicado este monográfico.

Conocí al profesor Barcia en el año 1991, en una casona de la zona de Retiro. Nos presentaron en una sala de muebles coloniales, pesados y oscuros. A través de una madura voz imponente como la suya y una tímida y joven que salió de mi garganta, empezamos a dialogar sobre cómo la literatura, su pasión, se podía unir con la mía, el cine. Apenas conocí su propuesta de la materia que había creado para inaugurar una carrera de Comunicación, sentí que habíamos arribado a ese punto de encuentro. Pedro no sólo creó y fundó Contenidos Culturales Contemporáneos, sino que fue el maestro de los muchos profesores jóvenes que comenzábamos a crecer en el mundo académico. Maestro de la vida, un gran profesor y humanista, prolífico escritor y editor, presidente de las Academias Argentinas de Letras y Educación durante muchos años, investigador del CONICET, doctor emérito de nuestra casa de estudios marcó y dio impronta a la nueva carrera que nacía en la Universidad Austral. Crecimos como profesores, como investigadores, como colegas, pero especialmente como personas, junto a él. Con su ejemplo desde el aula, he compartido veinticinco años la cátedra acompañándolo. Esa materia hoy ya no lo tiene al frente, pero gracias a su consejo y acompañamiento constantes es sostenida por el equipo que logró formar e intentamos continuar. Su texto La puerta en el muro nos describe cómo "se entra a la comunicación por la cultura" a través de tres hitos destacados de su trayectoria: la creación de la materia comentada, la publicación colectiva No seamos ingenuos. Manual para la lectura inteligente de los medios y el seminario La educación tecnológica. El doctor Barcia entiende por cultura la despejada definición de Ortega: "El conjunto de soluciones que una comunidad da a los problemas básicos de su existencia": la comunicación, la economía, la educación, el gobierno político, la religión, la política, las diversiones son ejemplos de ella. Seguidamente reflexiona cómo esa cultura se relaciona con la tecnología, presentada como una moneda de dos caras: una nos sirve y la otra nos condiciona. Será el desafío de la Universidad relevar y construir el delicado equilibrio entre ambas. Cuando una persona se convierte en adjetivo significa que su modo de ver el mundo y de construir un sello propio, han dejado una huella. La mirada barciana se descubre en su texto y contagia a quienes lo conocimos y compartimos. Ojalá que también contagie a las futuras generaciones y a los lectores de este monográfico. 
Austral Comunicación

Volumen 9, número 2 (Diciembre de 2020): 151-157. ISSN 2313-9129

\section{Referencias}

López Herrera, M.; López Aristica, M. y López Herrera L (2012). Cultura y Comunicación: una relación compleja. Contribuciones a las Ciencias Sociales. https:/www.eumed.net/rev/cccss/19/hah.html.

Rivadeneira Prada, R. (1990). Periodismo: la teoría general de los sistemas y la ciencia de la comunicación. México: Trillas. 